\title{
A educação escolar indígena e o desenvolvimento de talentos entre os Terena: desafios e perspectivas
}

\author{
Indigenous school education and talent development among Terena: \\ challenges and perspectives
}

\section{Educación escolar indígena y desarrollo del talento entre Terena: desafíos y perspectivas}

\section{Jane Farias Chagas-Ferreira}

Professora pós-doutora da Universidade de Brasília, Brasília, DF, Brasil

E-mail: janefcha@gmail.com ORCID: https://orcid.org/0000-0002-7087-8738

Recebido em 30 de agosto de 2021

Aprovado em 27 de setembro de 2021

Publicado em 27 de dezembro de 2021

\section{RESUMO}

O desenvolvimento dos talentos em comunidades não tradicionais é pauta emergente na educação de superdotados em vários países. Apesar dos avanços na legislação brasileira, ainda são incipientes as pesquisas com esta temática e inexistente 0 atendimento de alunos talentosos em comunidades indígenas. Diante desse desafio, este estudo de caso teve o objetivo de descrever como o talento é percebido e desenvolvido entre os Terena a partir da percepção de um de seus reconhecidos líderes. A recolha dos dados foi realizada por meio de análise documental e entrevistas. Os resultados evidenciaram a persistência de barreiras como: o preconceito e desconhecimento das potencialidades e talentos indígenas, a lacuna na formação de professores, a escassez de recursos e de oportunidades adequadas à diversidade cultural indígena. Com base nos resultados evidenciados, recomenda-se para pesquisas futuras a elaboração de indicadores para a formalização de processos de identificação e a oferta de atendimento educacional especializado para crianças e jovens Terena talentosos.

Palavras-chave: Talento ; Educação escolar indígena; Educação Especial.

\section{ABSTRACT}

The development of talents in non-traditional communities is an emerging issue in the education of gifted people in several countries. Despite advances in Brazilian legislation, research on this theme is still incipient and there is no assistance for talented students from indigenous communities. Faced with this challenge, this case study aimed to describe how talent is perceived and developed among Terena from the perception of one of their recognized leaders. Data collection was carried out through document analysis and interviews. The results showed the persistence of barriers such as prejudice and ignorance of indigenous potentialities and talent, the gap in teacher training, scarcity of resources, and opportunities appropriate to indigenous cultural diversity. Based on the results shown, it is 
recommended for future research to develop indicators for the formalization of identification processes and the provision of specialized educational assistance for Terena talented children and young.

Keywords: Talent; Scholar indigenous education; Special Education.

\section{RESUMEN}

El desarrollo del talento en comunidades no tradicionales es un problema emergente en la educación de personas con talento en varios países. A pesar de los avances en la legislación brasileña, la investigación sobre este tema aún es incipiente y no hay asistencia para estudiantes talentosos en comunidades indígenas. Frente a este desafío, este caso de estudio tuvo como objetivo describir cómo se percibe y desarrolla el talento entre Terena desde la percepción de uno de sus líderes reconocidos. La recolección de datos se realizó mediante análisis de documentos y entrevistas. Los resultados mostraron la persistencia de barreras como el prejuicio y la ignorancia de las potencialidades indígenas, la brecha en la formación docente, la escasez de recursos y oportunidades adecuadas a la diversidad cultural indígena. Según los resultados mostrados, se recomienda que las investigaciones futuras desarrollen indicadores para la formalización de los procesos de identificación y la provisión de asistencia educación especializada para niños y jóvenes Terena talentosos.

Palabras clave: Talento; Educación escolar indígena; Educación Especial.

\section{Introdução}

No Brasil, a comunidade indígena é constituída por mais de 300 povos que possuem línguas, costumes e crenças muito diferentes. Com isso, torna-se fundamental a compreensão de que cada cosmovisão e identidade étnica é única. Esse entendimento presume a necessidade de que se estabelecerem diálogos, convivências e relações simétricas. $O$ direto à diferença ou diversidade dos povos indígenas é agenda central dos movimentos indígenas em todo o mundo (CAVALCANTE, 2018; GENTRY; FUGATE, 2012).

$\mathrm{O}$ engajamento político de lideranças indígenas frente à atuação do poder público e de organismos internacionais e a modificação das leis brasileiras têm conferido aos indígenas pressuposto de igualdade com os demais brasileiros. Como sujeitos de direito, deixaram de ser legalmente considerados como "incapazes" e necessitados de tutela por não índios. Essa mudança de paradigma, ainda em curso, deveu-se, especialmente, pela atuação de movimentos indígenas de resistência, mobilização e conscientização (TERENA, 2016) e por um tom mais propositivo dado às reivindicações desses atores (ORÇO; ORÇO, 2017). Essa participação não se restringe, no entanto, ao âmbito político, mas reverbera em outras áreas da sociedade. De forma que, 
http://dx.doi.org/10.5902/1984686X67478

hoje, há índios com formação e inserção social suficiente para defender e discutir os direitos indigenista a partir de uma literatura produzida pelos próprios indígenas - seja o debate econômico, político, ecológico, agronegócio, jurídico, tecnológico, saúde, educação, ciência, entre outros (TERENA, 2016, s. p.).

Esse crescente protagonismo indígena e o avanço nas conquistas de direitos no âmbito local, nacional e global é assinalado por vários autores (AMADO, 2017; CAVALCANTE, 2018; MONTEIRO, 2019; ORÇO; ORÇO, 2017; SANTOS; FERREIRA, 2017). Paradoxalmente, as condições de continuidade de vida dessa população continua com uma lista infindável de ameaças, o que demonstra que "não são sujeitos de seus direitos na prática" (CAVALCANTE, 2018, p. 122). Essas ameaças tão presentes na contemporaneidade, entretanto, não the são restritas, visto que abarcam outras comunidades tradicionais que vivem nas florestas, nas caatingas sertanejas e às margens de nossos grandes rios. Como denuncia Silva (2018, p. 498), estes "passam a assumir vida de migrantes, adentrando nas filas do proletariado urbano ou nos bolsões de pobreza das grandes cidades".

Os avanços registrados com relação aos direitos fundamentais são inegáveis e assegurados tanto na Constituição de 1988, quanto por outros dispositivos legais e por ratificações de convenções internacionais feitas pelo governo brasileiro (BRASIL, 2019). Entretanto, também sinalizam um longo caminho a percorrer. Na contramão do que está preconizado nas normativas, salientam-se os processos educativos, de proteção do patrimônio cultural e relativas à inserção no mercado de trabalho, que ainda são lacunares e preocupantes.

Constam nas Diretrizes Curriculares Nacionais da Educação Escolar Indígena (BRASIL, 2012a) em seu artigo 11, que trata da Educação Especial, dispositivos para a oferta de recursos e serviços educacionais especializados para alunos com altas habilidades e superdotação. O Atendimento Educacional Especializado destina-se ao desenvolvimento de potencialidades socioeducacionais em todas as etapas e modalidades da Educação Básica Entre os desafios identificados para essa implementação, o parecer do Conselho Nacional de Educação aponta para a "ausência de formação de professores indígenas com relação a essa temática, a inadequação da infraestrutura dos prédios escolares, a falta de material didático específico e a falta ou inadequação do transporte escolar" (BRASIL, 2012b, p. 19).

É relevante ressaltar que a temática da educação especial em interface com a educação escolar indígena é recente (CAIADO; GONÇALVES; SÁ, 2017; SILVA; BRUNO, 2013), o que 
http://dx.doi.org/10.5902/1984686X67478

também é refletido na legislação, em documentos internacionais e em pesquisas que tratam da formação de professores para atuarem na Educação Escolar Indígena e na Educação Indígena (ver BRASIL, 2015; MENDES, 2019; ONU, 2008). Pelo menos pela via do estranhamento, vale a pena destacar um fragmento do Referencial Curricular Nacional para as Escolas Indígenas (BRASIL, 2002), que faz recomendações curiosas quanto à formação de professores para a elaboração de material didático e ilustração:

\footnotetext{
Vale destacar aqui que nem todas as pessoas possuem talento para a arte. Assim, no processo de preparação de livros ou de outros materiais, é recomendável que sejam ilustradores aqueles indivíduos - professores, alunos ou outras pessoas do grupo - que demonstram maior interesse, sensibilidade e aptidão para esse tipo de atividade, capazes de melhor captar, traduzir e comunicar as concepções estéticas e o sentimento de seu povo (BRASIL, 2002, p. 65).
}

A questão que fica é: quais foram as oportunidades de formação que os 22.590 professores que atuavam em 3.345 escolas indígenas, segundo dados do Censo Escolar Brasileiro (INEP, 2018), tiveram para desenvolverem essas potencialidades? E ainda, como poderão identificar entre os mais de 255.888 estudantes indígenas, aqueles que demonstram maior interesse, sensibilidade, aptidão e talento (não somente em arte, ou ilustração, mas em outras áreas), a fim de que sejam capazes de captar, traduzir e comunicar as concepções estéticas, o sentimento, a cultura e a identidade de seu povo? Tomando como base esse grande desafio, este estudo teve como objetivo descrever como o talento é percebido e desenvolvido entre os Terena a partir da percepção de um de seus líderes.

A literatura apresenta vários termos para designar pessoas altamente capazes como: talento, superdotação, altas habilidades, potenciais superiores, dotados, bem-dotados, precoces, gênio entre outros (RONDINI, 2019). Apesar desses termos nem sempre serem intercambiáveis a depender das teorias, neste estudo optou-se por utilizar os termos superdotação e talento como sinônimos, como utilizado por pesquisadores e publicações da área no contexto nacional e internacional (p. ex.: ALENCAR; FELITH, 2007; RENZULLI; REIS, 2018) e por minimizar mitos vinculados à superdotação que enfatiza esse fenômeno como algo raro, extremo e associado ao Quociente de Inteligência. O talento é definido tomando por base o "Modelo dos Três Anéis" de Renzulli (RENZULLI; REIS, 2014). No "Modelo dos Três Anéis", que considera a confluência de três fatores: habilidades acima da média (geral ou específica), criatividade e envolvimento com a tarefa. Renzulli e Reis (2014). Esse autores ainda categorizaram a superdotação em dois tipos: acadêmica e o produtivo-criativa. 
http://dx.doi.org/10.5902/1984686X67478

\section{O desenvolvimento dos talentos entre os povos indígenas}

O desenvolvimento dos talentos de comunidades não tradicionais e de grupos sub representados em programas e serviços educacionais para superdotados é pauta emergente na educação de vários países (CAMERON; CUTEAN, 2017; GENTRY; FUGATE, 2012; VIALLE, 2011). Essa temática tem recebido maior atenção nos últimos 10 anos, especialmente em países como o Canadá, Estados Unidos, Austrália e Nova Zelândia, por possuírem um grande contingente de imigrantes, comunidades nativas indígenas, assentados rurais, remanescentes de escravos ou população negra descendente de africanos, entre outros (HODGES; GENTRY, 2021). No Brasil, as pesquisas que envolvem esses grupos de pessoas talentosas ainda são escassas, no entanto, com relação ao talento entre indígenas, foram encontrados dois estudos realizados por professores da Universidade Federal do Amazonas.

O primeiro deles contou com participantes da etnia Sateré-Mawé, que vive numa área demarcada na calha central da Amazônia brasileira e tem uma população aproximada de 8.500 pessoas (BECKER; NINO; WEGEL, 2009). A pesquisa apresenta resultados de três momentos distintos de coleta de dados com professores, a partir de uma sensibilização sobre a Educação Especial. Os autores concluem que os professores possuem várias ideias que podem servir de base para a elaboração de propostas de ação para atender alunos indígenas que apresentam um potencial elevado.

O segundo estudo foi realizado com professores e estudantes da Etnia Mura que, em sua maioria, vivem na região de Autazes no Amazonas, e possui uma população aproximada de 9.300 indígenas (BECKER; MILON, 2012). Os professores responderam a uma lista de características de alunos superdotados e reconheceram que 26 dos 120 estudantes da escola tinham os atributos ali elencados. Os resultados demonstraram que os professores, apesar de não terem formação específica, identificaram características de superdotação acadêmicas e artísticas em seus alunos de forma a corroborar os aspectos definidos por Renzulli e Reis (2014), no Modelo dos Três Anéis. Esses professores assinalaram que privilegiavam a aceleração dos estudos dos estudantes que demonstravam habilidades superiores. Os estudantes, por sua vez, indicaram a necessidade de espaço, estrutura e recursos adequados para o desenvolvimento de suas habilidades.

Para que os talentos indígenas sejam desenvolvidos devem ser levados em consideração alguns fatores apontados por Gentry e Fugate (2012) e por outros colaboradores em Vialle (2011). Entre estes, foram destacados: (a) a estreita conexão que 
http://dx.doi.org/10.5902/1984686X67478

possuem com a natureza e os ecossistemas nos quais estão imersos; (b) a relação que mantém com seus antepassados, por meio da espiritualidade, que transcende os limites da vida e suas interações sociais; (c) os tempos e espaços em sua dinâmica comunitária; e (d) a maneira como os saberes são constituídos e construídos, em geral,pela observação e transmissão oral.

Ainda nesta direção, é pertinente que sejam adotados processos que propiciem a avaliação das potencialidades e talentos de maneira eficiente, por meio de instrumentos e procedimentos diferenciados como assinalado por outros autores (GENTRY; FUGATE, 201; VIALLE, 2011). De forma que, as habilidades e potencialidades identificadas acadêmicas, artísticas, emocionais, sociais, de liderança ou de outra ordem - sejam acolhidas adequadamente. A oferta de recursos e de atendimento especializado pode promover a inovação dos processos comunicativos com a sociedade envolvente, e, ainda, transformar as relações interétnicas entre esses povos por meio da disseminação e preservação do seu universo cultural. Universo que engloba os cantos, as danças, as pinturas corporais, as técnicas artesanais, a arte plumária, as rezas, os conhecimentos tradicionais. Devem incluir tanto a sabedoria dos anciãos quanto "as histórias contadas ao redor da fogueira, as brincadeiras das crianças, as festas e os rituais e todos os aspectos que integram as nossas formas culturais de viver e de ver o mundo" (JÓFEJ - KAINGANG, 2006, p. 132).

Nesse sentido, as políticas públicas devem abranger ações afirmativas, a flexibilização dos currículos escolares e seus processos avaliativos como estratégias sinalizadas para a inserção em serviços e programas já existentes. Estas iniciativas precisam avançar para a garantia de atendimento especializado coerente com as peculiaridades de cada comunidade tradicional, a fim de que tenham oportunidades e recursos necessários ao desenvolvimento dos talentos de suas crianças e jovens (CONNEI, 2009; GENTRY; FUGATE, 2012; VIALLE, 2011). Como postula Renzulli (2016), o talento é o capital social mais valioso de uma nação. Priorizar meios para desenvolvê-lo evitará um desperdício enorme de potencial humano.

\section{O povo Terena e seu legado histórico}

O estado do Mato Grosso do Sul concentra a segunda maior população de indígenas do Brasil. De acordo com Amado (2017), o território do povo Terena está localizado à oeste de Mato Grosso do Sul, coincidindo com uma parte do ecossistema do Pantanal e com os 
http://dx.doi.org/10.5902/1984686X67478

municípios de Miranda, Aquidauana, Anastácio, Sidrolândia, Dois Irmãos do Buriti, Nioaque e Rochedo, sendo que alguns grupos ocupam algumas áreas em São Paulo e Mato Grosso (MONTEIRO, 2019). Os Terena são a segunda mais extensa população indígena do Mato Grosso contando com aproximadamente 28 mil habitantes distribuídos por 10 Terras Indígenas, com mais de 40 aldeias.

Os Terena pertencem a um subgrupo da etnia Guaná ou Chané e fazem parte da família linguística Aruak, sendo considerado o grupo mais expressivo desta população (PEREIRA; PEREIRA, 2014). O idioma ainda falado é motivo de orgulho entre o povo. Suas tradições, cerâmica e práticas de agricultura são fortemente influenciadas por sua família linguística e pelos processos de aculturamento pelos quais passou (JESUS, 2007).

O povo Terena possui uma trajetória documentada desde o Século XVI e associada a outros povos indígenas, aos europeus, africanos e seus descendentes (BITTENCOURT; LADEIRA, 2000; JESUS, 2007). São descritos por vários autores como um povo ágil, ativo, inteligente, astuto e possuidor de um espírito resistente e firme de liberdade. São representados como bons agricultores, bons negociadores e possuidores de hábitos de higiene apurados e cuidado refinado com a aparência e a limpeza de suas casas (BITTENCOURT; LADEIRA, 2000; SANTOS; FERREIRA, 2017).

A produção cultural Terena é vasta, especialmente se considerarmos todos os registros históricos desse povo. Eles possuem inúmeros rituais entre os quais se destacam a "Dança da Ema" ou do "Bate-Pau" e a "Dança Putu-Putu" (JESUS, 2007). Ambas performadas por homens e mulheres, respectivamente, no dia 19 de abril, designado como Dia do Índio. Em tempos mais remotos, o artesanato era produzido essencialmente pelas mulheres, mas hoje ele tem garantido a subsistência e o resgate da arte ancestral de sua comunidade (GOMES, 2008; PEREIRA; PEREIRA, 2014). Os Terena influenciaram na maneira como as casas dos sertanejos brasileiros são construídas, na disseminação da mandioca como alimento e no fabrico da farinha e técnicas de tecelagem.

Eles tiveram uma participação decisiva em eventos relevantes na história do nosso país e no cenário internacional. A primeira delas é relacionada à Guerra do Paraguai ou da Tríplice Aliança, episódio determinante na demarcação das fronteiras do Brasil (PEREIRA, PEREIRA, 2014), mas que custou muito caro aos Terena, que perderam grande parte de seu território (GARCIA, 2017; XIMENES, 2017). Foram valorosos trabalhadores na construção de linhas telegráficas e na construção da ferrovia no noroeste do país. E ainda, há registros de que fizeram parte da Força Expedicionária Brasileira que lutou contra o 
http://dx.doi.org/10.5902/1984686X67478

nazismo nos campos italianos (GARCIA, 2017; SANTOS; FERREIRA, 2017, XIMENES, 2017). Estes fatos são marcadores das narrativas dos Terena, porque também tiveram um papel importante na desestabilização social, política e religiosa de seu povo (JESUS, 2007).

Atualmente, de acordo com Amado (2017), os jovens Terena têm uma presença importante nas universidades e em várias instâncias da gestão pública. Nesse sentido, há uma crescente preocupação com "a valorização da cultura e da língua, diante da capacidade sedutora do mundo estudantil, em especial a academia universitária que nunca aborda a importância dos ensinamentos tradicionais como parte curricular do novo "doutor". Diante desse cenário, Terena defende que seja criada uma Universidade dos povos indígenas e que estes deixem de ser apenas cotistas em ações de afirmação (TERENA, 2016).

A inserção na Universidade é vista não somente como uma forma de ascensão social, mas como instrumento de transformação e afirmação da cultura e como meio de superação da situação de exclusão experimentada pelos indígenas (MONTEIRO, 2019; TERENA, 1981, 1994, 2016). Esses jovens acadêmicos têm assento no Conselho do Povo Terena e se reúnem no âmbito do Programa Rede de Saberes. Eles participam ativamente do movimento indígena, como forma de darem alguma devolutiva para suas comunidades, qualificando a luta dos movimentos indígenas, por meio da participação em redes sociais, na gravação de vídeos e elaboração de material escrito (AMADO, 2017).

A partir de 2012, com a organização do Conselho do Povo Terena, as Assembleias se tornaram um marco importante no "despertar do povo" Terena. Essas assembleias envolvem toda a liderança Terena, inclusive professores e acadêmicos, e têm contado com a presença de outras lideranças indígenas. As reuniões do Conselho são realizadas anualmente desde 2014. A abrangência das assembleias se deve às discussões, pautas, tomadas de decisão e documentos que são elaborados acerca de temas fundamentais para a comunidade. Esses temas envolvem não somente a questão territorial, mas também educação, saúde, meio ambiente, sustentabilidade, representação política, juventude indígena e demandas das mulheres (AMADO, 2017). E, incluem, ainda políticas de representatividade em instâncias institucionais e governamentais.

De acordo com Amado (2017), os documentos finais dessas Assembleias são autênticos registros da situação vivenciada pelas comunidades indígenas e expressam a resistência ao modelo de desenvolvimento adotado pelo Estado brasileiro. Nesse sentido, Terena destaca: 
http://dx.doi.org/10.5902/1984686X67478

Os indígenas sentiram a necessidade de aprender a discutir os interesses da sua comunidade, os índios não precisam de um porta-voz, eles podem falar por si mesmos. E, ainda, "já chega do purutuyê [branco] falar por nós! Nós temos que falar por nós agora, é para isso que enviamos nossos jovens para as universidades, para competir de igual (Terena, citado em AMADO, 2017, p. 84).

Atualmente, os Terena, que ainda vivem nas aldeias, são valorizados como bons agricultores, bons comerciantes e por serem pessoas ordeiras (MONTEIRO, 2019). As aldeias possuem casas comunais e relações sociais dinâmicas. Apesar dessa dinâmica social ser de bi localidade, costumam ter forte vínculo com sua comunidade. É um grupo que mantém uma grande abertura para o exterior. Para Terena (2016), essa abertura envolveu, ao longo do tempo, a necessidade de se estabelecerem muitas alianças políticas, que se deram, acima de tudo, no único intuito de se manter e permanecer como povo, ainda que para isso tiveram que acionar outros símbolos e outros elementos culturais.

\section{Método}

Este estudo tem um delineamento qualitativo, exploratório e se constitui em um estudo de caso. Os estudos de caso visam investigar fenômenos sociais complexos, delimitados e contextualizados, sendo uteis para responder questões de pesquisa em áreas inexploradas (YIN, 2015).

\section{Participante}

Participou deste estudo de caso reconhecido líder Terena, nascido no Posto Indígena de Taunay, na aldeia de Bananal, perto de Aquidauana no estado do Mato Grosso do Sul. Como faz questão de acentuar "Terra Indígena dos Terena, filho e neto da tradição Xumono"'. Ele viveu em sua comunidade até os oito anos de idade, saindo de lá por conta das "agendas da vida como a necessidade de estudar, trabalhar e conhecer novos caminhos". Ao longo do estudo o participante escolheu para designá-lo o nome pelo qual é conhecido nacional e internacionalmente - Marcos Terena.

Marcos Terena estudou durante toda a Educação Básica em escolas em Campo Grande - MS. Após ingressar na Força Aérea Brasileira - FAB, foi aprovado em sua academia no Curso de Piloto Militar. Dois fatores o atraíram para o alistamento militar, naquela época, uma excelente opção: a pobreza e o fato de que com o uniforme "todos eram iguais". Tornou-se o primeiro piloto comercial indígena, profissão que desempenhou por mais de 32 anos (TERENA, 1992). Além dessa façanha pioneira, também é escritor, roteirista, comunicador e grande articulador político dos direitos indígenas, tendo 
http://dx.doi.org/10.5902/1984686X67478

contribuído com a elaboração de vários documentos nacionais e internacionais importantes e com a demarcação de terras indígenas de várias etnias.

Em função de sua reconhecida liderança, ocupou cargos de gestão na Fundação Nacional do Índio, no Ministério da Cultura e Memorial dos Povos Indígenas. É um dos idealizadores e coordenadores do Festival Nacional da Cultura e Tradições Indígenas e dos Jogos Mundiais Indígenas, em cuja primeira edição participaram 24 etnias nacionais e povos de 23 países, em 16 diferentes modalidades. Entre estas modalidades: arco e flecha, arremesso de lança, cabo de guerra, corrida de tora, lutas, futebol, atletismo, natação, canoagem, jogos de demonstração (ROQUE et al., 2017). Teve participação ativa na criação do Fórum Permanente sobre questões indígenas das Organizações Unidas - ONU, da Cátedra Indígena Internacional sobre o conhecimento tradicional e espiritualidade, Fórum Indígena Internacional sobre biodiversidade e na Conferência Mundial dos Povos Indígenas sobre Território, Meio Ambiente e Desenvolvimento. Com relação à sua trajetória pondera: "fui sendo considerado uma referência e/ou o chamado líder indígena mesmo sem viver na Reserva pelos chefes e pela opinião pública".

À época da pesquisa Marcos Terena tinha 66 anos, estava aposentado e era o coordenador geral dos Jogos Mundiais dos Povos Indígenas e estava empenhado na aproximação entre as mais de 20 aldeias Terena e de outros povos por meio da coordenação do Conselho Intertribal dos Povos Indígenas. Entre as grandes conquistas e mudanças que tem impulsionado e presenciado, foram por ele destacados: (1) a designação da Organização das Nações Unidas - ONU do dia 09 de agosto como o Dia Internacional dos Povos Indígenas; (2) a realização de um Documentário sobre o Idoso Indígena, que além de colocar em pauta essa temática pode também influenciar 0 pensamento intercultural da juventude fazendo uma junção entre a tradição e a modernidade; (3) a realização dos Jogos Mundiais dos Povos Indígenas, que em sua opinião, implicou a juventude em buscar e rebuscar seus valores na oralidade. Sendo, a seleção desses representantes realizada por livre determinação de cada liderança indígena: caciques, anciões e comandantes de equipe.

\section{Instrumentos}

Roteiro de entrevista semiestruturado. Para este estudo foi elaborado um roteiro de entrevista semiestruturado contendo um conjunto de perguntas subdividas em cinco categorias: (1) dados sociodemográficos; (2) o conceito de talento entre os Terena; (3) 
http://dx.doi.org/10.5902/1984686X67478

identificação de características individuais de pessoas consideradas talentosas; (4) estratégias e recursos disponíveis na comunidade para o desenvolvimento dos talentos; e (5) desafios a serem superados na identificação, promoção e desenvolvimento dos talentos entre os Terena.

Entrevista aberta. Após a análise do material produzido a partir do roteiro de entrevista semiestruturado, as zonas de sentido construídas foram discutidas com o participante com a finalidade de aprofundar e alinhas entendimentos sobre o fenômeno estudado e compreender a trajetória de desenvolvimento do talento do participante da pesquisa e suas percepções sobre a temática.

\section{Procedimentos de coleta de dados}

Inicialmente foi realizada busca e compilação de estudos empíricos e de publicações digitais em jornais, e-books e em audiovisuais disponibilizados em sites de pesquisa, blogs e repositórios institucionais como banco de teses de universidades, Portal CAPEs e Google acadêmico. O material compilado serviu como fonte para o levantamento de aspectos socio-histórico-culturais vinculadas aos valores, crenças e tradições Terena e como fonte biográfica sobre o participante da pesquisa, uma vez que há muito material jornalístico acerca de sua atuação política como indigenista.

Simultaneamente à análise documental, foi realizado contato com o participante por telefone que se mostrou acolhedor aos objetivos da pesquisa. No entanto, devido à sua agenda, o roteiro de entrevista semiestruturado foi respondido e enviado por e-mail junto com o Termo de Consentimento Livre e Esclarecido assinado. Nove meses depois, foi realizado contato com o participante utilizando-se o WhatsApp para aprofundar e alinhar o entendimento sobre os resultados da pesquisa. $O$ artigo em sua versão preliminar foi encaminhado por e-mail para sua revisão.

\section{Análise dos dados}

Os dados foram analisados por meio de procedimentos qualitativos interpretativos tendo como base princípios da Epistemologia Qualitativa de González-Rey, como o caráter construtivo-interpretativo e o diálogo (GONZÁLEZ-REIS, 2011). Nessa abordagem, a produção do conhecimento científico se dá por meio de um processo construtivointerpretativo, onde o diálogo e a comunicação se constituem em uma instância singular, relevante e necessária nessa elaboração. Nesse estudo, o participante, enquanto 
representante de seu povo, não é somente um informante, mas ganha o status de fonte histórica (MONTEIRO, 2019). Desta forma, pesquisador e pesquisado interatuam no processo de pesquisa, colaborando mutuamente com o entendimento do fenômeno estudado.

\section{Resultados}

\section{A definição de talento e a marcação temporal}

Ao longo da nossa entrevista, como também acontece com os relatos encontrados em outros estudos (DOMINGO; MARIA, 2017; JESUS, 2007; MENDES, 2019), foram evidenciados alguns marcadores temporais como: antigamente, antes ou depois da Guerra da Tríplice Aliança e da construção das ferrovias, com a chegada das missões... Esses marcadores vão delineando a percepção de quem eram, como viviam e como pensavam os Terena e o que são, como vivem e pensam nesse momento histórico. Passado e presente vão demarcando a reflexão e as possibilidades e demonstrando que a cultura está sempre em transformação. Nesse sentido, Marcos Terena argumenta que "não se pode comparar habilidades ou práticas de algum tipo de conhecimento entre a sociedade envolvente e uma Aldeia Indígena. Os parâmetros sempre serão diferentes”. E indica que "cada povo tem seu sistema de identificar habilidades, crenças e o respeito em relação aos outros".

Marcos Terena menciona que, antigamente, quando a mulher tinha um papel fundamental na educação tradicional Terena, as habilidades e talentos eram considerados um dom. Nesse tempo, eram as mulheres que educavam as crianças até aos 9 ou 10 anos, repassando os fundamentos de sua cultura, língua e valores. A maioria delas não falava 0 português e como guardiãs da língua, por meio de canções e histórias ensinavam sobre o seu povo e o seu habitat. Somente na adolescência, os meninos começavam a aprender com outros adultos questões sobre a economia doméstica e comunitária e a andar pela floresta. O participante relembra que "nesse tempo. quando os educadores podiam ser os pais, as mulheres e os mais velhos, qualquer tipo de habilidade era considerado um dom, mas que carecia de um aconselhamento maior para evitar principalmente a vaidade". Para ele, os Terena reconhecem que cada criança tem um espírito único com talentos próprios.

Ademais Marcos Terena enfatiza que - com a chegada na aldeia "das igrejas evangélicas, do exército e com a Guerra da Tríplice Aliança e a estrada de ferro do trem do 
http://dx.doi.org/10.5902/1984686X67478

Pantanal" - os homens índios tiveram que desenvolver outras habilidades, uma vez que "passaram a ser orientadores do homem branco. Isso é muito importante". O contato com a sociedade envolvente transformou não somente os valores tradicionais, mas também as formas de convivência entre eles.

Atualmente, na percepção de Marcos Terena, depois da criação de escolas pautadas na educação bilíngue e intercultural, apesar das diretoras e professoras serem, geralmente, da própria aldeia, os valores indígenas não foram e não são incorporados no currículo oficial da escola. "Os professores tendem a se apoiar e a apoiar seus alunos nos valores ocidentais". Nesse sentido, os talentos indígenas são valorizados quando e se "corresponderem às expectativas do investidor educacional". Em sua percepção, "ainda perdura o sintoma colonialista que age como protetor, paternalista ou coercitivo, afinal as regras pré-determinadas vêm de um mundo estranho para o indígena". A essa questão reage, "foi por isso que em 1981 ainda estudante, escrevi um lema para a juventude indígena: "Posso ser o que você é, sem deixar de ser quem sou!"

Essa valorização de habilidades e conhecimentos estranhos à comunidade indígena leva ao distanciamento dos valores tradicionais, mas por outro lado, descortina e inaugura novas perspectivas e possibilidades também. Essa percepção fica evidente na constatação de que atualmente há "(...) muitos jovens indígenas que estão formados em engenharia, agronomia, engenharia florestal, pedagogia e outras profissões como gerentes, pastores etc. É um quadro novo de situações que começa". Essa nova realidade, coloca em destaque os valores ocidentais que foram acessados, a inteligência da pessoa e as oportunidades oferecidas. Essa conquista, no entanto, não é vista ou valorizada como "um mérito de "vencedor", ainda que seja uma conquista relevante para a comunidade". Nesta direção, Marcos Terena sinaliza que "a comunidade, a família ou o clã se mantém vitorioso em silêncio, pois o pensamento é de que amanhã, haverá outro vitorioso também".

Uma outra face dessa nova realidade demonstra que esses jovens precisaram - e ainda precisam - romper com muitos preconceitos, percorrer e abrir caminhos, lutar por igualdade de direitos e por acesso a oportunidades que outros brasileiros já têm garantidos. Um episódio na trajetória de Marcos Terena é icônico e ilustrativo de como os mitos e preconceitos são fatores impeditivos ao desenvolvimento dos talentos indígenas e está registrado no livro "O Índio Aviador" (FEIJÓ; TERENA, 1994). Apesar de passar em condições de igualdade técnica e intelectual em provas, testes e exames físicos, sempre tendo que fazer mais do que outros estudantes até chegar a ser aviador, teve o seu sonho 
http://dx.doi.org/10.5902/1984686X67478

de pilotar um avião comercial de grande porte interrompido, sob o parecer de que sendo índio, era, portanto, "incapaz". Sua persistência encontrou nos poderes públicos a oferta de que deveria se emancipar, ou seja, "deixar de ser índio". A batalha na justiça levou três anos até que houvesse um parecer favorável ao seu pleito! No entanto, é evidente que muitos talentos têm sido desperdiçados, historicamente, entre os indígenas "pelo simples fato de sermos diferentes, trataram-nos como preguiçosos, obstáculos ao desenvolvimento, pagãos e selvagens" (TERENA, 2000).

Internamente, na cultura Terena, para que uma pessoa seja reconhecida e valorizada pela comunidade como uma pessoa talentosa na área da liderança é necessário que suas práticas estejam alinhadas aos valores tradicionais de sua cultura. "Se elas aprenderam os ensinamentos de seus pais e avós, será considerada uma liderança e de alguma forma começará a exercer esse papel para o bem da Comunidade, será ouvida e conquistará a responsabilidade, por exemplo, de conselheira". Na percepção de Marcos Terena, o maior castigo que se deve aprender a evitar e o mais caro para um Terena está relacionado com a humilhação, isolamento e desconsideração tribal.

\section{Os Terena e o desenvolvimento dos talentos}

Toda a comunidade, as divisões familiares e clãs fazem parte do processo da formação das pessoas e essa é uma característica das comunidades tradicionais. Não há um destaque especial para uma atividade específica, o talento emerge "na evolução da vida e do cotidiano e se estabelece na relação entre o aluno e o mestre. Faz parte do dia a dia sem qualquer destaque especial para isso". Nesse sentido, "ninguém na Aldeia se torna um hábil flecheiro, canoeiro, caçador ou artesão sem o acompanhamento de seu Mestre, que pode ser a própria família e no decorrer do tempo, compartilhado com outros membros da Comunidade".

Mesmo que, em algum momento, a pessoa talentosa seja destacada para a atividade na qual demonstra maior potencial, habilidade ou competência técnica ela terá as mesmas responsabilidades que os demais membros de sua comunidade - "a rotina dela seguirá a mesma de outras crianças, jovens e adultos". Ainda que essas pessoas venham a se sobressair e a conquistar lugares que outros membros da comunidade ainda não haviam alcançado, elas estarão firmadas nos valores e conhecimentos que aprenderam na aldeia. Esses ensinamentos são a base de sua formação e servem de bússola pelo caminho. E, quando recebem algum destaque ou conquistam esse lugar de destaque, constituem em 
http://dx.doi.org/10.5902/1984686X67478

exemplo para os mais jovens. Nesse sentido, Marcos Terena testemunha que a base de todo o seu conhecimento foi aprendido em sua aldeia com os ensinamentos orais de seus pais e avós. Esse conhecimento perdura ainda hoje, apesar de, em sua aldeia, ninguém sequer poderia prever que ele chegaria a ser um piloto de avião ou articulador indígena internacional. No entanto, "em algum momento com base nesse olhar de meus mais velhos, e isso acontece com todos, tive que assumir esse papel e agora, já mais velho, como um condutor que pode servir de espelho aos mais novos".

Marcos Terena defende que os indígenas que recebem destaque pessoal não devem ser constrangidos ou serem responsabilizados para que retornem às suas aldeias, como forma de retribuição. Esse posicionamento não deve ser algo imposto, mas deve estar vinculado a suaprópria consciência como indígena. São os seus referenciais tradicionais que os aproximam de seu povo, mesmo sob forte preconceito ou discriminação. São esses referenciais que os motiva, que fortalecem sua identidade étnica, elevam a autoestima e promovem conquistas inéditas. Nesse contexto, relata: nossa tradição Terena ensina-nos a agir sob as bênçãos e inspiração do Grande Ituko-Oviti e assim, sem jamais perder esse referencial foi possível aproximar-me da minha Aldeia, mesmo distante, com projetos..." que visavam a melhoria de condições de vida, a demarcação de terras ou afirmação da identidade. É preciso muita determinação para vencer o preconceito, que no caso de sua região, sempre foi muito forte e até hoje sobrevive "sob o apelido discriminatório de "bugre".

Os jovens que se preparam ou são identificados como líderes espirituais recebem atenção diferenciada dos mais velhos. Esse é um "dom" que, na percepção de Marcos Terena, não se determina e não se transfere. Ademais, o indígena, independentemente de ser protestante ou católico, "sempre terá sua confiança no Grande Espírito que os Guarani chamam de Nhanderu e os Terena de Ituko-Oviti, e isso ninguém pode tentar interpretar ou transformar em uma religião, pois é a sagrada relação de vida".

Em síntese, é importante salientar que a grande riqueza dos povos indígenas do Brasil são os seus valores ancestrais e ambientais distribuídos em mais de 300 sociedades, que falam um universo de mais de 220 línguas. Infelizmente, devido a ideias preconceituosas e estereotipadas, muitas delas ainda vinculadas aos processos colonizadores ou ideologias colonizadoras, desconsideram a indissociabilidade entre o território e a identidade indígena.

$\mathrm{Na}$ opinião de Marcos Terena, o compromisso de todo líder indígena, seja nas articulações políticas pelos direitos humanos e ambientais, seja na busca por uma aliança com a sociedade do novo milênio é fazer prevalecer o entendimento de que o índio não 
http://dx.doi.org/10.5902/1984686X67478

precisa adotar os valores da comunidade envolvente para ser valorizado. Seu valor é intrínseco ao seu estilo de vida, está na diversidade de sua cultura e nas suas potencialidades. E, enfatiza:

O índio morre quando tem sua identidade violada através do não reconhecimento de seus valores espirituais e culturais a partir da demarcação de seus territórios. O homem branco precisa sobreviver como seja, e por isso ele suporta mudar de sua terra, mas o Índio sabe que ele só é forte quando está dentro de sua terra de origem.

Dois grandes desafios ainda foram apontados, não somente para o índio, mas também para o negro e as pessoas pobres que vivem nas periferias das cidades e estão relacionados com a geração de emprego e renda. Essas pessoas ainda permanecem vitimizadas por suas condições socioeconômicas, tendo que superar uma ampla lista de vulnerabilidades e barreiras. Ainda ficou registrada a compreensão da necessidade de uma maior conscientização sobre a importância do investimento nos talentos entre essas comunidades. No que tange ao universo indígena, essa conscientização merece profunda reflexão que perpassa a percepção que o próprio índio tem de si mesmo e de suas potencialidades. Esse entendimento foi expresso por Marcos Terena por meio de uma pergunta: "o índio que gosta de contar histórias, ele poderia ser um futuro político, mas será que ele pensa assim?"

\section{Discussão}

Os resultados evidenciam uma nova realidade experimentada, não somente pelos Terena, mas por outras comunidades indígenas no Brasil, especialmente no que tange à participação ativa de movimentos indígenas na formulação de políticas públicas voltadas a garantia de direitos humanos fundamentais e o crescente envolvimento de jovens em eventos de cunho cultural e esportivo. No entanto, ficou também implícita a distância entre as normativas e sua efetiva implementação, motivo ainda de muitas lutas e resistências.

No campo da Educação Escolar Indígena, do ponto de vista da análise documental ensejada neste estudo, ficou constatado que seus documentos norteadores (diretrizes, orientações pedagógicas e curriculares) trazem pouca informação sobre a Educação Especial, limitando-se às definições gerais de seu público-alvo, exceptuando-se parecer do Conselho Nacional de Educação (BRASIL, 2009) que define algumas limitações para a implementação de atendimento especializado, destacando-se a formação de professores, a elaboração de material didático especifico e a melhoria das condições de transporte e 
http://dx.doi.org/10.5902/1984686X67478

infraestrutura escolar. Também não foram encontrados programas ou serviços destinados ao desenvolvimento de crianças e jovens com altas habilidades ou superdotação em comunidades de indígenas. Constatação que vai na contramão da crescente iniciativa por identificação e atendimento desses indivíduos em outros países com contingentes significativos de povos nativos e comunidades tradicionais (GENTRY; FUGATE, 2012; VIALLE, 2011).

Com relação ao atendimento especializado de superdotados no Brasil, os dados de pesquisas acadêmicas e os relatórios dos censos escolares brasileiros são convergentes e têm demonstrado um crescimento estatístico ainda pouco representativo da área (CARNEIRO; FLEITH, 2017). Sendo indicada a necessidade de maiores investimentos na formação de professores, no registro das informações escolares e na continuidade e expansão de programas e serviços destinados a essa população estudantil. O que se torna ainda mais urgente, quando se trata de estudantes talentosos indígenas.

O povo Terena tem uma reconhecida trajetória de contribuição ao desenvolvimento nacional, que se constitue em marcadores históricos que sinalizam tanto as suas conquistas passadas e presentes, quanto os seus movimentos de resistência. Nesse sentido, na percepção de nosso participante, pensar o talento envolve não perder de vista as potencialidades de crianças e jovens, mas também requer o compromisso com a cultura, as crenças e valores da comunidade tradicional, sem deixar de reconhecer as demandas de cada tempo. Essa ideia corrobora o entendimento de que a definição de talento não é estática. Trata-se de um construto que vai sendo cunhado em função das dinâmicas de vida de cada grupo social e não possui uma compreensão única. Nesta direção, vários autores destacam que a definição de superdotação ou talento é um construto social que terá implicações na maneira como esse capital social será identificado, reconhecido, valorizado e atendido (OUROFINO; FLEITH, 2011; RENZULLI; REIS, 2014).

Apesar de muitos Terena terem a bi localidade como uma realidade imposta pelos novos tempos, há uma preocupação das lideranças indígenas de que continuem sendo quem são, com sua cosmovisão única, falantes de sua língua, orgulhosos de sua identidade como índios. Sendo assim, as escolas em suas aldeias, os professores e os currículos não podem prescindir da cultura do povo Terena: suas tradições, suas artes, sua espiritualidade, seus valores. É esse conjunto que deve nortear as práticas pedagógicas e os conteúdos curriculares em toda a Educação Básica. Nesse contexto, a entrada cada vez mais recorrente de jovens Terena na universidade (tanto nos cursos de graduação quanto pós- 
http://dx.doi.org/10.5902/1984686X67478

graduação) revela uma preocupação crescente com uma formação mais contextualizada e a criação de espaços que os levem a terem uma atuação mais efetiva tanto na comunidade envolvente quanto no meio de seu povo.

Pensar no talento Terena implica pensar em uma gama de diferentes habilidades que vão sendo requeridas historicamente pelas demandas de inserção social e pela demarcação de seu território e sua identidade. Com isso, são assinaladas conquistas no âmbito das relações internas e externas, como a participação em Conselhos e Organismos Nacionais e Internacionais e a organização do Conselho Indígena. No entanto, a identificação precoce dos talentos é fundamental como uma ação de incentivo, qualificação e articulação no sentido de fomentar não somente a produção, mas o fortalecimento das culturas indígenas e ainda como forma de ampliar sua representação: simbólica, econômica e cidadã. $O$ investimento no desenvolvimento dos talentos Terena deve ainda refletir na melhoria das condições de vida de sua própria comunidade.

Foram destacadas algumas barreiras que se impõem às crianças e jovens Terena, que associadas ao acesso a oportunidades, aos estereótipos sociais, a inexistência de formação específica de professores para atuarem com os talentos indígenas e a necessidade de serem elaborados currículos contextualizados nas Escolas Indígenas e universidades. Sendo estes últimos denunciados como espaços que, por vezes, desprivilegiam a cultura, os saberes, as técnicas, a língua, os estilos de vida e a religiosidade dos povos indígenas. Essas barreiras são, muitas vezes, ensejadas pela falta de regulamentação de leis ou pela própria falta de conscientização da comunidade e suas lideranças sobre a importância e a necessidade de investimento no desenvolvimento dos talentos (GENTRY; FUGATE, 2012; VIALLE, 2011).

A concepção de talento entre os Terena, como acontece com outros grupos sociais, parece ter se transformadoao longo do tempo, sendo mediada principalmente pela maneira como as práticas educativas parentais foram sendo modificadas no âmbito da família. Nessa dinâmica, o papel originalmente atribuído à mulher Terena foi substituído pelo sistema escolar. O talento visto como um dom, inicialmente, parece englobar uma ampla variedade de habilidades e competências associadas ao campo das artes, da política, da liderança e profissão.

Apesar do reconhecimento de grandes lideranças, do destaque que vários acadêmicos, advogados e artistas e profissionais de outros campos recebem fora da comunidade Terena, prevalecem os aspectos socioculturais da tradição Terena, que têm 
como valor central: a comunidade, a humildade, a relação de subordinação às lideranças locais e aos anciãos. Como enfatizou Marcos Terena, "todo o sucesso conquistado não é mérito de um indivíduo, mas de toda a comunidade que representa. Sendo esperado que esse sucesso seja compartilhado e vivenciado por outros membros da comunidade".

Nesse processo de compreensão da importância do investimento adequado no desenvolvimento das potencialidades e talentos indígenas é necessário um movimento de conscientização dos próprios indígenas para que se vejam como protagonistas de novos tempos e de novas possibilidades de atuação como construtores de sua própria história e identidade.

o índio não tem que ficar justificando sua produção, seus princípios, sua cultura. Ainda que o seu talento e a expressão de sua produção não aconteçam dentro da aldeia. O que ele faz, não é somente para ele, é para toda a sociedade. Ele deve ser autêntico, deve avançar, sem esquecer os rastros de seus antepassados.

\section{Considerações finais}

Os resultados desta pesquisa apontam para aspectos já delineados na literatura da área e que se aplicam ao efetivo desenvolvimento dos talentos indígenas como a necessidade de investimento na formação de professores, na produção de materiais didáticos e em recursos e equipamentos necessários à identificação e atendimento de crianças, jovens e adultos talentosos. Enfatizando, ainda, a necessidade de que, nesse processo, sejam consideradas as especificidades de cada povo: seus saberes, suas ciências, suas artes, suas espiritualidades e história. Tudo isso em diálogo com os demais saberes produzidos em outras sociedades humanas (BRASIL, 2012A).

Para pesquisas futuras, recomenda-se o estudo ampliado com crianças e jovens indígenas que demonstram possuir talentos relacionados a habilidades tradicionais como: contação de histórias, música tradicional, artesanato, como também em liderança, negociação, facilidade para aprender, entre outros. Ainda sinalizamos a necessidades de que sejam elaborados indicadores para a oferta de atendimento educacional especializado em Escolas de Educação Indígena, por meio de procedimentos de avaliação e identificação que levem em consideração as especificidades e diversidade cultural de comunidades tradicionais específicas.

Fica evidente que temos todos uma "grande dívida social que não admite moratória" com as questões indígenas em nosso país. E, nesse sentido, é imperativo não somente a demarcação de terras, mas fazer ecoar as palavras de Terena, no sentido de nos 
engajamos na garantia dos direitos que já estão estabelecidos, provendo as condições, os recursos e as oportunidades para que crianças e jovens indígenas expressem todas as suas potencialidades.

Queremos descobrir o Brasil com nossos próprios códigos, buscando recriar um novo tempo (...). Nós, os índios, não queremos continuar como os grandes mudos da história, pois o milagre dos sonhos também existe e precisamos ter mentes fortes para concretizá-lo (TERENA, 2000, s.p.).

\section{Referências}

AMADO, Luís Henrique Eloy. O despertar do povo Terena para os seus direitos: movimento indígena e confronto político em Mato Grosso do Sul. MovimentAção, v. 4, n. 6, p. 83-104, 2017. Disponível em: https://doi.org/10.30612/mvt.v4i06.7674. Acesso em: 06 jan. 2020.

BECKER, Maria Alice; MILON, Helândia Feitosa. Estudos em altas habilidades no Amazonas. Revista AMAzônica, v. 5, n. 3, p. 220-257, 2012. Disponível em: acesso em:

BECKER, Maria Alice; NINO, Carlos Guilhermo Rojas; WEIGEL, Valéria. Pesquisa na área Sateré-Mawé: a descoberta de talentos indígenas. Psicologia Escolar e Educacional (ABRAPEE), v. 13, n. 1, p. 55-63, 2009. Disponível em: https://doi.org/10.1590/S1413-85572009000 100007. Acesso em: 16 dez. 2019.

BITTENCOURT, Circe Maria; LADEIRA, Maria Elisa. A história do povo Terena. Brasília: Ministério da Educação - MEC, 2000.

BRASIL. Ministério da Educação e Cultura. Referencial Curricular Nacional para as Escolas Indígenas. Brasília: MEC/SEF, 2000.

BRASIL Ministério da Justiça. Estatuto dos Povos Indígenas. Proposta da Comissão Nacional de Política Indigenista. Brasília: Ministério da Justiça, 2009. Disponível em: http://www.funai. gov.br/arquivos/conteudo/presidencia/pdf/Estatuto-doIndio_CNPI/Estatuto_Povos Indige nas-Proposta_CNPI-2009.pdf. Acesso em: 04 jan. 2020.

BRASIL. Diretrizes Curriculares Nacionais da Educação Escolar Indígena na Educação Básica. Diário Oficial da União, v. 121, n. 1, p. 7, 2012 a. ISSN 1677 - 7042.

BRASIL. Conselho Nacional de Educação. Parecer Conselho Nacional de Educação/CEB 13/12. Brasília: MEC/CNE, 2012b. Disponível em: http://portal.mec.gov.br/index.php? option=com_docman\&view=download \&a lias=10806-pceb013-12-pdf\&Itemid=30192. Acesso em: 06 dez 2019.

BRASIL. Diretrizes Curriculares Nacionais para a Formação de Professores Indígenas em cursos de Educação Superior e de Ensino Médio. Resolução CNE/CP 1/2015. Diário Oficial da União, Brasília, Seção 1, p. 11-12, 2015. 
http://dx.doi.org/10.5902/1984686X67478

BRASIL. Decreto no. 10.088, de 5 de novembro de 2019. Diário Oficial da União, v. 234A, Seção 1, p. 1-7, 2019.

CAIADO, Kátia Regina Moreno; GONÇALVES, Taísa Grasiela Gomes Liduenha; SÁ, Michelle Aparecida de. Educação escolar no campo: desafios à educação especial. Linhas Críticas, v. 22, n. 48, p. 324-345, 2017. Disponível em: https://doi.org/10.26512/lc.v22i48.4887. Acesso em: 10 jun. 2021.

CAMERON Alicia.; CUTEAN, Alexandra. Digital Economy Talent Supply: Indigenous Peoples of Canada, Information and Communications Technology Council. Ottawa, Canada, 2017. Disponível em: https://www.ictc-ctic.ca/wpcontent/uploads/2017 /06/Indigenous_Supply_ICTC FINALENG. pdf. Acesso em: 06 jan. 2020.

CARNEIRO, Liliane Bernardes:; FLEITH, Denise de Souza. Panorama brasileiro de atendimento ao aluno superdotado. Revista de Estudios e Investigación en Psicología y Educación, v. 11, n. Extra, p. 259-263, 2016. Disponível em: https://doi.org/10.20435/1984-042X-2016-v.18-n.1(05). Acesso em: 15 jan. 2020.

CAVALCANTE, Breno Neno Silva. Povos indígenas e a luta por direitos do lado de lá da linha abissal. Vukápanavo: Revista Terena, v. 1, n. 1, p. 107-124, 2018. Disponível em: https://www. vukapanavo.com/. Acesso em: 12 dez. 2019.

CONNEI. I Conferência de Educação Escolar Indígena. Documento Final, 2009. Disponível em: http://www.educadores.diaadia.pr.gov.br/arquivos/File/pdf/deliberacoes_ coneei.pdf. Acesso em: 06 jan. 2020.

DOMINGO, Sandra Ventura-; MARIA, Elisângela Castedo. Análise do comportamento socioambiental Terena por meio de marcadores espaço-temporais: uma contribuição para a conservação da cultura. Interações, v. 18, n. 1, p. 59-73, 2017. Disponível em: https://doi.org/10.20435/1984-042X-2016-v.18-n.1(05). Acesso em: 06 jan. 2020.

FEIJÓ, Ateneia-; TERENA, Marcos. O índio aviador. São Paulo: Moderna, 1994.

FLEITH, Denise de Souza; ALENCAR, Eunice Maria L. Soriano. (Orgs.)

Desenvolvimento de Talentos e Altas Habilidades - Orientação a pais e professores. Porto Alegre: Artmed, 2007.

HODGES, Jaret; GENTRY, Marcia. Underrepresentation in Gifted Education in the Context of Rurality and Socioeconomic Status. Journal of Advanced Academics, v. 32, n. 2, p. 135-159, 2021. Disponível em: https://journals.sagepub.com/doi/pdf/10.1177/ 1932202X20969143. Acesso em 20 ago. 2021.

GARCIA, Adilso de Campos Garcia; CASTILO, Maria Augusta de. A Guerra do Paraguai e a usurpação dos territórios indígenas. Revista do Exército Brasileiro, v. 153, n. Edição Especial, p. 77-86, 2017. Disponível em: http://ebrevistas.eb.mil.br/index. php/REB/article/view/1355. Acesso em: 06 jan. 2020.

GENTRY, Marcia; FUGATE, Mattheu. Gifted native American students: underperforming, under-identified, and overlooked. Psychology in the Schools, v. 49, n. 7, p. 631-646, 2012. Disponível em: https://doi.org/10.1002/pits.21624. Acesso em: 21 jan. 2020. 
http://dx.doi.org/10.5902/1984686X67478

GOMES, Luciana Scanoni; KABAD, Juliana Fernandes. A produção da cerâmica pelas mulheres Terena: interfaces entre cultura material, gênero e território tradicional. In: REUNIÃO BRASILEIRA DE ANTROPOLOGIA. Porto Seguro, Bahia, 2008. Anais. Disponível em: https://docplayer.com.br/9624188-A-producao-da-ceramica-pelasmulheres-terena-interfaces-entre-cultura-material-genero-e-territorio-tradicional-1.html. Acesso em: 12 jan. 2020.

GONZALEZ REY, Fernando Luis. Pesquisa qualitativa em psicologia: caminhos e desafios. São Paulo: Cengage Learning, 2011.

INEP. Instituto Nacional de Estudos e Pesquisas Educacionais Anízio Teixeira. O Censo Escolar da Educação Básica. Resumo Técnico e Notas Estatísticas. Brasília: MEC/INEP, 2018. Disponível em: http://portal.inep.gov.br/web/guest/resultados-eresumos. Acesso em: 06 jan. 2020.

JESUS, Naine Terena. Kohixoti-Kipáe: a Dança da Ema - memória, resistência e cotidiano Terena. Dissertação de Mestrado. 2018. 132f. (Departamento de Arte). Universidade de Brasília, Brasília, 2018. Disponível em: https://repositorio.unb.br/bitstream/ 10482/3753/1/2007NaineTerena deJesus. PDF. Acesso em: 06 jan. 2020.

JÓFEJ - KAINGANG, Lúcia Fernanda. A proteção legal do patrimônio cultural dos Povos Indígenas no Brasil. In V. Araújo et. al. (Orgs), Povos Indígenas e a Lei dos "Brancos": o direito à diferença. Brasília: Ministério da Educação, Secretaria de Educação Continuada, Alfabetização e Diversidade; LACED/Museu Nacional, p.122-145, 2006.

MENDES, Simone Rodrigues Batista. Formação de Professores e Educação Indígena: Projeto Magistério Indígena Tamî'kan. Boa Vista: Editora da Universidade Federal de Roraima, 2019.

MONTEIRO, Luciano Araújo. Os Terena na história. Tellus, v. 19, n. 39, p. 227-241, 2019. Disponível em: https://doi.org/10.20435/tellus.v19i39.561. Acesso em: 18 jan. 2020.

ORÇO, Cláudio Luís; ORÇO, João Paulo. A Formação de Professores Indígenas no Brasil. Unoesc \& Ciência, v. 8, n. 2, p. 135-142, 2017. Disponível em:

https://portalperiodicos.unoesc.edu.br/achs/article/view/15860. Acesso em 25 jan.2020.

OUROFINO, Vanessa Terezinha Alves Tentes; FLEITH, Denise de Souza. A condição underachievement em superdotação: definição e características. Psicologia: Teoria e Prática, v. 13, n. 3, p. 206-222, 2011. Disponível em: http://pepsic.bvsalud.org/pdf/ ptp/v13n3/v13n3a16.pdf. Acesso em: 15 nov. 2019.

RENZULLI, Joseph. Reflections on Gifted Education: critical works by Joseph S. Renzulli and colleagues. Waco, Texas: Prufrock Press, 2016.

RENZULLI, Joseph; REIS, Sally. Schoolwide Enrichment Model. 3. ed. Mansfield, CT: Prufrock Press, 2014. 
RENZULLI, Joseph; REIS, Sally. The three-ring conception of giftedness: a developmental approach for promoting creative productivity in young people. In (Eds.) S.I. PFIEFFER; E. SHAUNESSY-DEDRICK; M. FOLEY-NICPON. APA Handbook of Giftedness and Talent, 2018, pp. 185-199. American Psychological Association. Disponível em: https://psycnet.apa.org/record/2017-32525-012. Acesso em: 20 set. 2021.

RONDINI, Carina. Caminhos e descaminhos na formação docente para o trabalho com os estudantes com altas habilidades/ superdotação. Revista Docente, n. 11, v. 22, p. 79-94, 2019. Disponível em: https://www.revformacaodocente.com.br/index.php/rbpfp/ article/view/246/219. Acesso em: 20 set. 2021.

ROQUE, Luca; TERENA, Marcos; CALFIN, Juan Antônio.; TERENA, Taily. Jogos mundiais dos povos indígenas: Brasil, 2015: o importante é celebrar! Brasília: PNUD, 2017. Disponível em: https://unesdoc.unesco.org/ark: /48223/pf0000249170. Acesso em: 06 jan. 2020.

PEREIRA, Luana Roberta Oliveira de Medeiros; PEREIRA, Marcus Vinícius Medeiros. Fazendo música com a cultura Terena. Música na Educação Básica, Londrina, v. 6, n. 6, p. 1-33, 2014. Disponível em: http://abemeducacaomusical.com.br/revista_musica/ed6/ Revista\%20Musica\%206_Luana.pdf. Acesso em: 20 jan. 2020.

SÁ, Michele Aparecida de. Educação e escolarização de criança indígena com deficiência em Terra Indígena Araribá. 2015. 184 f. Tese (Doutorado em Ciências Humanas) - Universidade Federal de São Carlos, São Carlos, 2015. Disponível em: https://repositorio.ufscar.br/bitstream/handle/ufscar/2935/6702.pdf?sequence=1\&isAllowed =y. Acesso em: 10 jun. 2021.

SANTOS, Cesar Christian Ferreira; FERREIRA, Giselle Vasconcelos dos Santos. A participação dos Terena e guaicurus na retirada da laguna sob a perspectiva literária da obra de Taunay. Revista Philologus, v. 23, n. 67, p. 290-300, 2017 Disponível em: https://www.filologia.org.br/rph/ANO23/67supl/012.pdf. Acesso em: 06 jan. 2020.

SILVA, Elizângela Cardoso de Araújo. Povos indígenas e o direito à terra na realidade brasileira. Serviço Social \& Sociedade, v. 133, set/dez, p. 480-500, 2018. Disponível em: https://doi.org/10.1590/0101-6628.155. Acesso em: 09 dez. 2019.

SILVA, João Henrique; BRUNO, Marilda Moraes Garcia. A formação de professores para o Atendimento Educacional Especializado nas escolas indígenas de Dourados - MS: impactos e desafios. I Simpósio Internacional de Estudos sobre Deficiência DEDPcD/Diversitas/USP, Anais, São Paulo, junho 2013. Disponível em: http://www.memorialdainclusao.sp.gov.br/ebook/Textos/Joao_Henrique_da_Silva.pdf. Acesso em: 10 jun. 2021.

TERENA, Mariano Marcos. O problema de fazer parte da comunidade brasileira enquanto brasileiros e enquanto membros de determinada etnia. Cadernos Ceru, v. 16, p. 33-45, 1981.

TERENA, Mariano Marcos. Cidadãos da Selva: a história contada pelo outro lado. Rio de Janeiro: Gráfica GB, 1992. 
http://dx.doi.org/10.5902/1984686X67478

TERENA, Mariano Marcos. Uma palavra indígena 500 anos depois. Folha de São Paulo, opinião, 2000. Disponível

em: https://www1.folha.uol.com.br/fsp/opiniao/fz0201200009.htm. Acesso em: 02 dez. 2019.

TERENA, Mariano Marcos. Entrevista: Marcos Terena conta um pouco de sua história. Canal UKA TV, Uberlândia - MG, 2016. Disponível em: https://www.youtube.com/watch?v=3Vz_RMaTSjk. Acesso em: 06 Jan. 2020.

VIALLE, Wilma (Eds.). Giftedness from an Indigenous Perspective. Melbourne: AAEGT/University Wollongong Printery, 2011.

XIMENES, Lenir Gomes. Os Terena e a consolidação do Estado Brasileiro. Revista do Exército Brasileiro, v. 153, Edição Especial, p. 65-76, 2017. Disponível em: http://ebrevistas.eb.mil.br/index.php/REB/article/view/1355. Acesso em: 06 jan. 2020.

YIN, Robert K. Estudo de caso: planejamento e métodos. (5ํe. ed.). Porto Alegre: Bookman.

\section{Notas}

${ }^{1}$ De acordo com Amado (2017) existem duas tradições entre os Terena: (a) Xumono que significa gente brava e (b) Sukirikianó, gente mansa.

(c) (1) (8)

This work is licensed under a Creative Commons Attribution-NonCommercial 4.0 International (CC BY-NC 4.0) 